\title{
Effect of Biology, Climatic and Bioclimatic Applied Studies on Plant: to Increase the Economy and Maintaining Food Security in the Jerusalem Occupied of Palestine
}

\author{
*Jehad M. H. Ighbareyeh ${ }^{1,2}$, A. Cano-Ortiz ${ }^{1}$, E. Cano Carmona ${ }^{1}$, Mohammed M. H. \\ Ighbareyeh $^{1}$, Asmaa A. A. Suliemieh ${ }^{1}$ \\ ${ }^{1}$ Department of Animal and Plant Biology and Ecology, Faculty of Experimental Sciences, \\ University of Jaen, Spain. \\ ${ }^{2}$ Department of Biology Applied, Faculty of Science Applied, \\ Palestine Polytechnic University, Hebron, Palestine \\ jehadighbareyeh@hotmail.com
}

\begin{abstract}
A Plum (Prunus domestica L.) is a species of flowering plant in the family Rosaceae, it is one of the most important export crops in Palestine. We analyzed the mean annual temperature and precipitation using data from one weather station of the Palestine Meteorological Department, recorded in the period from 19932012 (19 years), with the same years plant production (rain-fed) from the Palestinian Central Bureau of Statistics (PCBS). Statistical tests included a bioclimatic analysis of Palestinian meteorological station for the period previous by using bioclimatic classification of the Earth of Rivas Martinez Salvador, with regard to simple continentaly index, compensated thermicity index, annual ombrothermic index, water deficit and soil water reserve. In concluded, both climatic and bioclimatic factors play a very important role in plant biology, in the production, sustainability of crop yield and lead to an increase in economy in Jerusalem, when we applied a principal component analysis (PCA), observed that the type plots were located at the right of axis 1 during (1997-2002 and 2002-2007) affected by the bioclimate factor as annual ombrothermic index and simple thermicity index, and climate factors as precipitation during (1993-1997) in Jerusalem, while type plots were located at the left axis 1 during and during (1997-2002) influenced by mean monthly temperature, deficit water and water soil reserve in Jerusalem. Furthermore, in the inframediterranean to thermomediterranean environments, the optimum for the production of plum is achieved with values of annual ombrothermic index (24), simple continentaly index value between 15 to 22, and compensated thermicity index from $350-450$ in Jerusalem.
\end{abstract}

Keywords: Palestine, Jerusalem, biology, bioclimatic and yield.

\section{INTRODUCTION}

A Plum (Prunus domestica L.) is a fruit of the subgenus Prunus of the genus Prunus. The subgenus is distinguished from other subgenera (peaches, cherries, bird cherries, etc.), and it's a species of flowering plant in the family Rosaceae, subfamily amygdaloideae [1].

Globally, the long term analysis of climate changes and their biological effect showed that they have an impact on species' physiology, species distribution, organisms' phenology, and biocenosis composition and dynamics [2]. (Parmesan \& Yohe, 2003). Worldwide, according to Intergovernmental Panel on Climate Change (IPCC), the total increase in global temperature from 1850 to 2005 is $0.76^{\circ} \mathrm{C}$, and heating rate average over the last 50 years is almost twice as in the past 100 years. Rainfall, Plums grow best in areas where rainfall occasionally falls during the summer and the humidity stays low. Dry leaves and fruit during the growing season discourage plant disease. Most plant diseases attack plum trees when the weather is wet for an extended period of time.

Plums may have been one of the first fruits domesticated by humans [3]. Three of the most abundant cultivars are not found in the wild, only around human settlements: Prunus domestica has been traced to East European and Caucasian mountains, while Prunus salicina and Prunus simonii originated in Asia. It is remains have been found in Neolithic age archaeological sites along with olives, grapes and figs $[4,5]$. Plums are produced around the world, and China is the world's largest producer in 2013 [6] and different cultivars of plums in Palestine as Damson, Greengage, Victoria plums. 
Recent studies [7-21] have highlighted the influence of bioclimatology and climatology applied on biology, yield, physiology and growth of plant; however this is the first time the bioclimatic characterization of the different varieties has been under taken. Palestine is belonging to the inframediterranean to mesomediterranean of bioclimatic belts; and arid, semiarid, dry, sub-humid and humid of ombrotype [9].

Jerusalem is the capital of Palestine occupied by Israel since 1948, and so far, which is also one of the oldest cities in the world. Today, the status of Jerusalem remains one of the core issues in the IsraeliPalestinian conflict. During the 1948 Arab-Israeli War, West Jerusalem was among the areas captured and later annexed by Israel while East Jerusalem, including the Old City, was captured and later annexed by Jordan. Israel captured East Jerusalem from Jordan during the 1967 Six-Day War and subsequently annexed it. During its long history, Jerusalem has been destroyed at least twice, besieged 23 times, attacked 52 times, and captured and recaptured 44 times.

The climate of Jerusalem is said to be ideal, with its relatively high altitude ensuring warm, dry summer weather with low humidity, and contrasting chilly, wet winters. Snow may fall in winter but is a rarity that is greeted as a novel experience by locals. Summer days are sunny and pleasant with temperatures averaging comfortably around $75^{\circ} \mathrm{F}\left(24^{\circ} \mathrm{C}\right)$. In the shoulder seasons of spring and autumn Jerusalem sometimes experiences the hot, dry desert wind known as the sharav or khamsin, traditionally believed to blow for 50 days out of the year. Jerusalem today, however, seems to have a generally uniform climate and is in a specially favored location to experience an ideal climate. It is not too hot, not too cold, not too dry, not too wet. Bioclimatology is the discipline that studies the relationship between climates and living organisms. Jerusalem bioclimatic belt belongs to the inframediterranean and thermomediterranean of thermotype and arid to subhumid ombrotype [9,20].

Aim study the effect of climatic, biology and bioclimatology applied on plum (Prunus domestica L.) to establish the variables that had the greatest influence on plant yield to increase the economy and maintaining food security in the region of Jerusalem occupied in Palestine.

\section{Materials AND Methods}

\subsection{Study Area}

Jerusalem is located in the middle of Palestine and between some of cities, where western of Jericho and Jordan river, east of Ramallah, the northern of Bethlehem and Hebron, south of Nablus and Jenin and others cities. in general, it is located between the Dead Sea of the western, Mediterranean Sea and the mountains Mediterranean Basin region, which include the Mount of Olives (East) and Mount Scopus (North East). The elevation of the Old City is approximately $760 \mathrm{~m}(2,490 \mathrm{ft})$ and with a Coordinates: $31^{\circ} 47^{\prime} \mathrm{N} 35^{\circ} 13^{\prime} \mathrm{E}$, the whole of Jerusalem is surrounded by valleys and dry riverbeds (wadis).

\subsection{Data Analysis}

We indicated to data taken from the East Jerusalem (which occupied in 1967) with the knowledge that many of the areas have been taken over by Israel from 2000 and so far in Jerusalem. Data were used from the meteorological station in Jerusalem for the years 1993 to 2012, and for the same years for production of plant (Table 1) and (Fig. 1). The bioclimatology of the aforementioned station was studied, and the value of the bioclimatic indices as annual ombrothermic index (Io), simple continentally index (Ic), and compensated thermicity index (It/Itc) and the climatic factors were obtained according to Salvador Rivas-Martinez [22- 26].

Table1. Independents variables (climate and bioclimate factors) and dependent factors (Plant production) from 1993-2012 in Jerusalem

\begin{tabular}{|l|r|r|r|r|r|r|r|r|}
\hline Years & \multicolumn{1}{l|}{ T } & \multicolumn{1}{l|}{ P } & \multicolumn{1}{l|}{ Df } & \multicolumn{1}{l|}{ R } & \multicolumn{1}{l|}{ It/Itc } & \multicolumn{1}{l|}{ Ic } & \multicolumn{1}{l|}{ Io } & \multicolumn{1}{l|}{ Production of Plum } \\
\hline $1993-1997$ & 18.9 & 549 & 576 & 413 & 422 & 17.4 & 2.26 & 604 \\
\hline $1997-2002$ & 19.9 & 511 & 618 & 444 & 475 & 16.1 & 1.89 & 500 \\
\hline $2002-2007$ & 18.1 & 577 & 566 & 398 & 390 & 18.9 & 2.48 & 580 \\
\hline $2007-2012$ & 19.3 & 533 & 586 & 408 & 433 & 18.6 & 2.32 & 550 \\
\hline
\end{tabular}

Yield: Kg. dunum. 


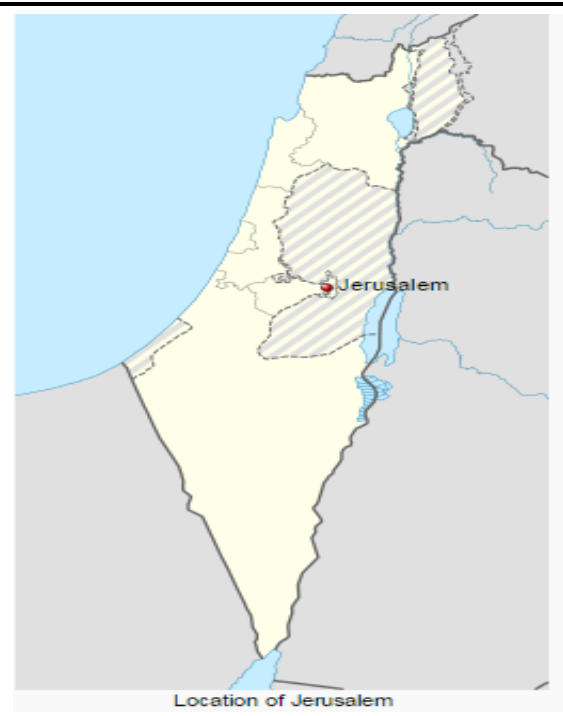

Fig1. Location of Jerusalem of Palestine

Moreover, we analyzed the relationship between the dependent variable as apple production; the independent variables consists of (climate factors) such as mean monthly temperature $(\mathrm{T})$, precipitation (P), soil water reserves (R), and deficit water (Df), and (bioclimate factors ) as annual ombrothermic index (Io), simple continentally index (Ic), and compensated thermicity index (It/Itc), in this study, the Shapiro-Wilk and Jarque-Bera normality tests were applied [27-30], and the p-value was obtained for the seven variables. We applied analysis of variance (ANOVA) linear regression analysis to each of the eight independent and dependent variables, the three bioclimatic variables and the four remaining physical variables (climate factors), and each of the dependent variable plum yield, in order to obtain corresponding analysis (CA) and the principal component analysis (PCA) were subsequently applied to determine the influence of independent variables on production. These statistical analyses were done using the XLSTAT software.

\section{RESUlTS AND DISCUSSION}

Bioclimatic is study or relating to the relations of climate and living matter. Rivas Martinez methodology [22], determines a generic world-wide climate classification in five macrobioclimates (tropical, Mediterranean, temperate, boreal and polar) on the basis of bioclimatic indexes. However, we used the bioclimatic classification of earth to Salvador Rivas-Martinez to analyses of the climate factors and bioclimatic parameters (independent variables) to study the relationship between physical factors of climate and bioclimate, and plant production, the plant sustainability and increase the economy in the occupied Jerusalem, knowing that only study in East Jerusalem (occupied in the 1967 war and not in 1948 by Israel). After application of the Shapiro-Wilk normality test [29, 30], the pvalue obtained from the variables studied tended to be below 0.05 , a conventionally accepted value.

\subsection{Principal Component Analysis}

Principal component analysis (PCA) was used to help identify the variables different, using factor extraction with an eigenvalue $>1$ after varimax rotation. The results of PCA, including the factor loadings with a varimax rotation as well as the eigenvalues, are tabulated in (Table 2). Three of the eigenvalues were found to be $>1$ and the total variance for the three factors is about $(90.136 \%)$. Factor 1 was dominated by all climate as soil water reserves (0.975), mean monthly temperature (0.956), and deficit water (0.991), and bioclimate factors as compensated thermicity index (0.993), while negatively factors as annual ombrothermic index, simple continentally index and precipitation with accounts for $(90.136 \%)$ of the total variance. Factor 2 is a dominated by compensated thermicity index, deficit water, mean monthly temperature, while negatively to the rest of factors, and accounts for $(6.405 \%)$ of the total variance. This factor represents, effect, and interesting of compensated thermicity index, deficit water, mean monthly temperature on growth, production and sustainability of plant, therefore, its effect on the productivity of plant and increased economic in these area. Factor 3 is a highly dominated by mean monthly temperature $(0.268)$, simple continentally index $(0.11)$, deficit water, while negatively to the rest of factors, and accounts for $(3.459 \%)$ of the total variance (Table 2). 
However, when we applied a principal component analysis (PCA), observed that the type plots were located at the right of axis 1 during (1997-2002 and 2002-2007) affected by the bioclimate factor as annual ombrothermic index and simple thermicity index, and climate factors as precipitation during (1993-1997) in Jerusalem, while type plots were located at the left axis 1 during and during (19972002) influenced by mean monthly temperature, deficit water and water soil reserve in Jerusalem, with a large proportion of the variance explained by axes 1 (90.14 \%) and axes 2 (6.40\%) (Fig. 2). Nevertheless, plum trees prefer good-draining soil sandy soil in order to thrive, but survive wet winter soil. The soil should be medium moist most of the time for best growth. Plums tolerate dry soil in drought conditions, they prefer a soil with a $\mathrm{pH}$ that ranges from 5.5 to 6.5. It is always a good idea to have your soil tested before planting any fruit tree to be sure that they $\mathrm{pH}$ is appropriate. Choose a location with full to filtered sun exposure, which encourages full flowering and fruit development. A location with a slope or raised area for planting the plum trees is best; do not plant in a low area where frost settles in the spring. Furthermore, the plum trees were adapted in dry to humid regions which are characterized by moderate summer with temperature between $15-30^{\circ} \mathrm{C}$, which had to obtain high quality of production and Mediterranean and lower mesomediterranean environments [20].

Table2. Factors loading and eigenvalue of the PCA and variables data (dependent and independent factors)

\begin{tabular}{|l|r|r|r|}
\hline \multicolumn{1}{|c|}{ Variables } & F1 & F2 & \multicolumn{1}{|c|}{ F3 } \\
\hline T & 0.956 & 0.119 & 0.268 \\
\hline P & -0.957 & -0.139 & -0.255 \\
\hline Df & 0.991 & 0.102 & -0.091 \\
\hline R & 0.975 & -0.179 & -0.131 \\
\hline It/Itc & 0.993 & 0.036 & 0.110 \\
\hline Ic & -0.886 & 0.457 & 0.079 \\
\hline Io & -0.982 & 0.179 & 0.066 \\
\hline Production of Plum & -0.845 & -0.440 & 0.303 \\
\hline Eigenvalue & 7.211 & 0.512 & 0.277 \\
\hline Inertia (\%) & 90.136 & 6.405 & 3.459 \\
\hline Variance \% & 90.136 & 96.541 & 100.000 \\
\hline
\end{tabular}

Biplot (axes F1 and F2: $96.54 \%$ )

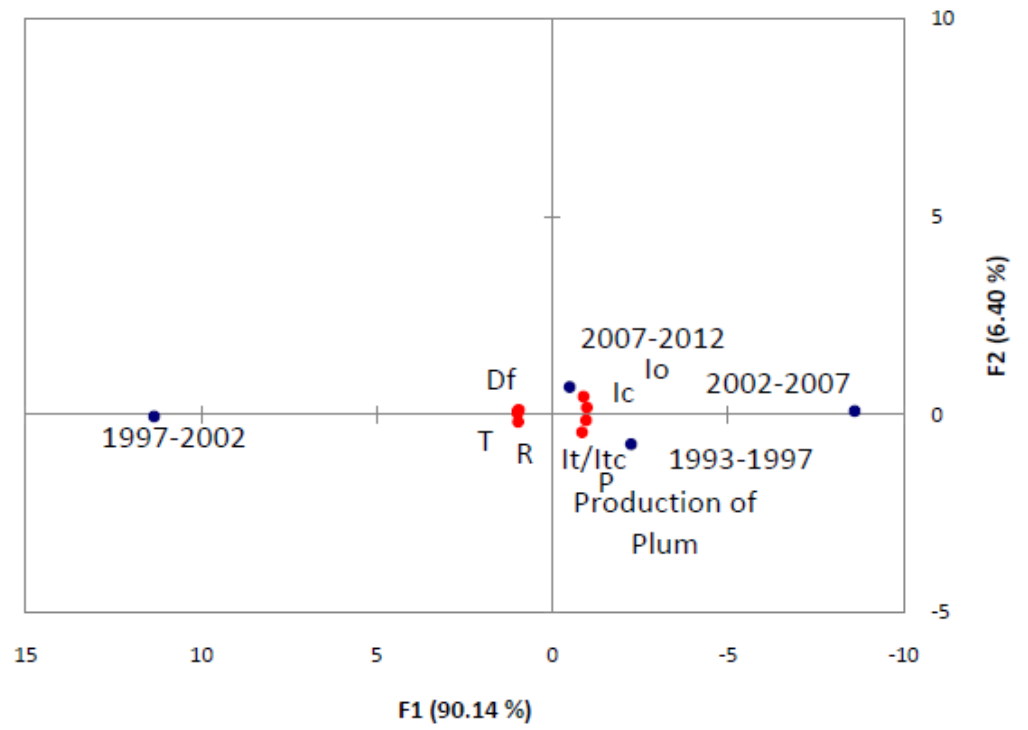

Fig2. Graphic of principal component analysis to independent and independent variable

\subsection{Corresponding Analyses}

Correspondence analysis (CA) is a multivariate statistical technique proposed [31] by Hirschfeld [32] and later developed by Jean-Paul Benzécri [33]. It is conceptually similar toprincipal component analysis, but applies to categorical rather than continuous data. In a similar manner to principal component analysis, it provides a means of displaying or summarizing a set of data in twodimensional graphical form. When we analyzed correspondence analysis is applied to each of the dependent variables and the seven physical parameters (independent variables), significant differences $(\mathrm{P}<0.05)$ can once again be observed in all cases. In view of the linear correlation obtained, we 
applied a correspondence analysis (CA). This was done by comparing the dependent variables plum production with the total independent variables and the three bioclimatic parameters Io, Ic and It/Itc. In the first place it was observed that the type plots are located at the right of axis 2 affected by the bioclimate factors of simple thermicity index, annual ombrothermic index and climate factor as precipitation during 2002- 2007 in Jerusalem, and in the second place type plots reveal the influence of water deficit and water soil reserve during 1997-2002, while influenced by mean monthly temperature and compensated thermicity index, with a large proportion of the variance explained by axis 1 (92.66\%), and axis 2 (6.36\%) (Figure 3). As in the inframediterranean to thermomediterranean environments, the optimum for the production of plum is achieved with values of Io (2-4) in Jerusalem and the rest of Palestine. Furthermore, Jerusalem is located in the arid, semiarid, upper dry, and with a little sub humid territory [7-16].

In the other side, the average temperature in Plum is $9.7^{\circ} \mathrm{C}$. in a year, the best temperature for storing plums is about $31^{\circ}-32^{\circ} \mathrm{F}$ with relative humidity around $90 \%-95 \%$; if kept at this temperature, plums may last for 2 to 4 weeks, regarding the distribution of cultivars depending on "flowering starting", it was found that it starts from February 1, having 55-70 days.

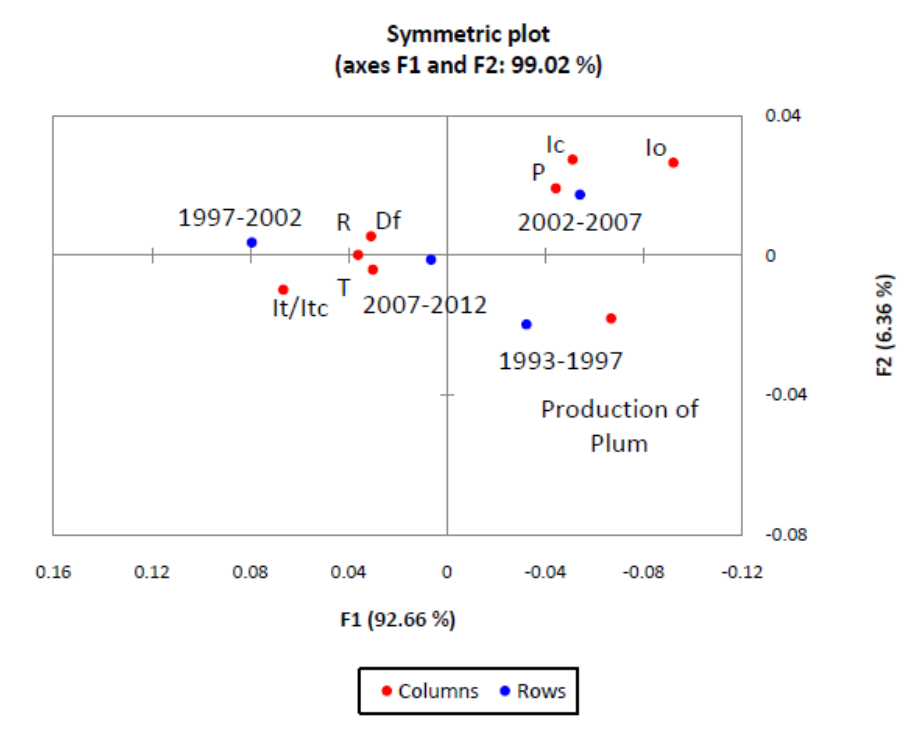

\section{CONClusion}

Both climatic and bioclimatic factors play a very important role in plant biology, in the production, sustainability of crop yield and lead to an increase in economy in Jerusalem therefore, during (19972002 and 2002-2007) affected by the bioclimate factor as annual ombrothermic index and simple thermicity index, and climate factors as precipitation during (1993-1997), while during (1997-2002) influenced by mean monthly temperature, deficit water and water soil reserve in Jerusalem. Furthermore, in the inframe diterranean to therm omediterranean environments, the optimum for the production of plum is achieved with values of annual ombrothermic index (2-4), simple continentaly index between (15 - 22), and compensated thermicity index from (350 - 450) in Jerusalem, also the plum trees were adapted in dry to humid regions which are characterized by moderate summer with temperature between $15-30^{\circ} \mathrm{C}$, which had to obtain high quality of production and Mediterranean and lower mesomediterranean environments.

\section{REFERENCES}

[1] D. Potter, T. Eriksson, R. C. Evans, S. Oh, J. E. E. Smedmark, D. R. Morgan, M. Kerr, K. R. Robertson, M. Arsenault, T. A. Dickinson \& C. S. Campbell "Phylogeny and classification of Rosaceae". Plant Systematic and Evolution 266 (1-2): 43.doi:10.1007/s00606-007-0539-9. (2007).

[2] Parmesan, C., Yohe, G. A globally coherent fingerprint of climate change impacts across natural systems. Nature 421: 37-42. (2003).

[3] Jules Janick, ed. Horticultural Reviews (Volume 23). Wiley. ISBN 978-0471254454. (1998).

[4] Jules Janick "The origins of fruits, fruit growing and fruit breeding" Purdue University. (2005). 
[5] Spangenberg; et al. "Chemical analyses of organic residues in archaeological pottery from Arbon Bleiche". Journal of Archaeological Science 33 (1): 113. doi:10.1016/j.jas.2005.05.013. (January 2006).

[6] "Production of Plum by countries". UN Food \& Agriculture Organization. (2013).

[7] Ighbareyeh J. M. H., Cano-Ortiz, A. and Cano, E. Biological resources management in Palestine, Department of Animal and Plant Biology and Ecology, Faculty of Experimental Sciences, University of Jaen, Jaen, Spain, doctorate thesis, p 102-105. (2014).

[8] Ighbareyeh, J. M. H., A. Cano-Ortiz \& E. Cano. Biological and bioclimatic basis to optimize plant production: Increased economic areas of Palestine. Agricultural Science Research Journal 4(1); pp. 10- 20, 2014. Available online at http://www.resjournals.com/ARJ , ISSN: $2026-6332$ (C)2014 International Research Journals. (2014).

[9] Ighbareyeh, J.M.H., Cano-Ortiz, A. and Cano, E. Case Study: Analysis of the Physical Factors of Palestinian Bioclimate. American Journal of Climate Change, 3, 223-231. http://dx.doi.org/10.4236/ajcc.2014.32021. (2014).

[10] Ighbareyeh, J. M. H., Cano-Ortiz, A., Suliemieh, A. A. A., Ighbareyeh, M. M. H. and Cano, E. Phytosociology with Other Characteristic Biologically and Ecologically of Plant in Palestine. American Journal of Plant Sciences, 5, 3104-3118. http://dx.doi.org/10.4236/ajps.2014. 520327. (2014).

[11] Ana Cano Ortiz, Jehad M.H. Ighbareyeh, Eusebio Cano. Bioclimatic Applications and Soil Indicators for Olive Cultivation (South of the Iberian Peninsula. Global Advanced Research Journal of Agricultural Science (ISSN: 2315-5094) Vol. 3(12) pp. 433-438, www.arcjournals.org. (2014).

[12] Ighbareyeh Jehad M. H., A. Cano-Ortiz, E. Cano Carmona, Mohammed M. H. Ighbareyeh, Asmaa A. A. Suliemieh. Study of Biology and Bioclimatology of Date Palm (Phoenix Dactylifera L.) To Optimize Yield and Increase Economic in Jericho and Gaza Cities of Palestine, International Journal of Research Studies in Biosciences (IJRSB) Volume 3, Issue1, January 2015, PP 1-8, ISSN 2349-0357 (Print) \& ISSN 2349-0365 (Online). www.arcjournals.org. (2015).

[13] Ighbareyeh, J. M. H., Cano-Ortiz, A., Suliemieh, A.A.A., Ighbareyeh, M. M. H. and Cano, E. Assessment of Biology and Bioclimatology of Plant to Increase Economic in Palestine. International Journal of Research Studies in Biosciences (IJRSB) Volume 3, Issue 3, March 2015, PP 1-8 ISSN 2349- 0357 (Print) \& ISSN 2349-0365, www.arcjournals.org. (2015).

[14] Ighbareyeh, J. M. H., Cano-Ortiz, A., Suliemieh, A. A. A., Ighbareyeh, M. M. H. and Cano, E. Biology and Bioclimatology Applied on Plant in Palestine, International Journal of Research Studies in Biosciences (IJRSB) Volume 3, Issue 3, March 2015, PP 79-86 ISSN 2349-0357 (Print) \& ISSN 2349-0365 (Online) www.arcjournals.org. (2015).

[15] Ighbareyeh, J.M.H., Cano-Ortiz, A., Suliemieh, A. A. A., Ighbareyeh, M.M.H. and Cano, E. Assessing Crop Yield Sustainability under the Climatic and Bioclimatic Change in the Area of Palestine. American Journal of Climate Change, 4, 48-56. http://www.scirp.org/journal/ajcchttp://dx.doi.org/ 10.4236/ajcc.2015.41005. (2015).

[16] Ighbareyeh J. M. H., A. Cano-Ortiz, E. Cano Carmona, Mohammed M. H. Ighbareyeh, Asmaa A. A. Suliemieh. "Study Effect of Biology and Bioclimatology Applied on Plant in the Area of Hebron at the South of Palestine" has since been reviewed and it is accepted for publication in Volume 3, Issue 5, May 2015, PP 56-64, ISSN 2349-0357 (Print) \& ISSN 2349-0365. (2015).

[17] Ighbareyeh J. M. H., A. Cano-Ortiz, E. Cano Carmona, Mohammed M. H. Ighbareyeh, Asmaa A. A. Suliemieh. Effect of Biology and Bioclimatology Applied On Plant in the Area of Jenin at the North of Palestine, International Journal of Research Studies in Biosciences (IJRSB) Volume 3, Issue 6, June 2015, PP 1-6 ISSN 2349-0357 (Print) \& ISSN 2349-0365. (Online) www.arcjournals.org. (2015).

[18] Ighbareyeh Jehad M. H., A. Cano Ortiz, Eusebio Cano Ortiz, Mohamed M. H. Ighbareyeh and Asmaa A. A. Suliemieh. Study of climatology and bioclimatology applied on plant in area of Hebron in Palestine, International Multidisciplinary Research Journal, Volume - 5, Issue - 1, July - 2015, ISSN 2231-5063. (2015). 
Effect of Biology, Climatic and Bioclimatic Applied Studies on Plant: to Increase the Economy and Maintaining Food Security in the Jerusalem Occupied of Palestine

[19] Ighbareyeh J. M. H., A. Cano-Ortiz, E. Cano Carmona, Mohammed M. H. Ighbareyeh, Asmaa A. A. Suliemieh. Modeling of Biology and Bioclimatology Applied on Plant in Palestine. Swift Journal of Agricultural Research Vol 1(3) pp. 021-027 July, http://www.swiftjournals.org/sjar. (2015).

[20] Ighbareyeh J. M. H., A. Cano-Ortiz, E. Cano Carmona, Mohammed M. H. Ighbareyeh, Asmaa A. A. Suliemieh. Effect of Biology and Bioclimatology Applied Studies on Plant in the Area of Jerusalem in Palestine, International Journal of Research Studies in Biosciences (IJRSB), Volume 3, Issue 9, September 2015, PP 135-140, ISSN 2349-0357 (Print) \& ISSN 2349-0365 (Online) www.arcjournals.org. (2015).

[21] Ighbareyeh, J.M.H., Cano-Ortiz, A., Suliemieh, A. A. A., Ighbareyeh, M.M.H. and Cano, E. Study of Biology and Bioclimatology Applied of Apricot (Prunus Armeniaca L.): to Increase the Economy and Maintaining Food Security in Palestine, International Journal of Research Studies in Biosciences (IJRSB), Volume 4, Issue 2, February 2016, PP 12-20, ISSN 2349-0357 (Print) \& ISSN 2349-0365 (Online), www.arcjournals.org. (2016).

[22] Rivas Martinez S., Sanchez Mata D. and Costa M. North American boreal and western temperate forest vegetation (Syntaxonomical synopsis of the potential natural plant communities of North America, II). Itinera Geobot. 12: 5-316. (1999).

[23] Rivas Martínez, S. Clasificación bioclimática de la Tierra. Folia Bot. Matritensis. 16:1-20. (1996).

[24] Rivas Martinez, S. Worldwide Bioclimatic Classification System. www.globalbioclimatics.org. (2004).

[25] Rivas-Martínez S., Rivas-Sáenz S., Penas A. Worldwide Bioclimatic Classification System. Global Geobotany vol. 1:1-634. (2011).

[26] Rivas-Martinez, S. Global bioclimatic, Internet: http://www.globalbioclimatics.org. (2008).

[27] Jarque, C., Bera, A. Efficient tests for normality homoscedasticity and serial independence of regression residuals. Econometric Letters 6, 255-259. (1980).

[28] Jarque, C., Bera, A. A test for normality of observations and regression residuals. International Statistical Review 55, 163-172. (1987).

[29] Shapiro, S., Wilk, M 1965. An analysis of variance test for normality (complete samples). Biometrika 52, 591-611. (1965).

[30] Shapiro, S., Wilk, M., Chen, H. A comparative study of various tests for normality. Journal of the American Statistical Association 63, 1343-1372. (1968).

[31] Dodge, Y. The Oxford Dictionary of Statistical Terms, OUP ISBN 0-19-850994-4. (2003).

[32] Hirschfeld, H.O. "A connection between correlation and contingency", Proc. Cambridge Philosophical Society, 31, 520-524. (1935).

[33] Benzécri, J.-P. L'Analyse des Données. Volume II. L'Analyse des Correspondances. Paris, France: Dunod. (1973). 